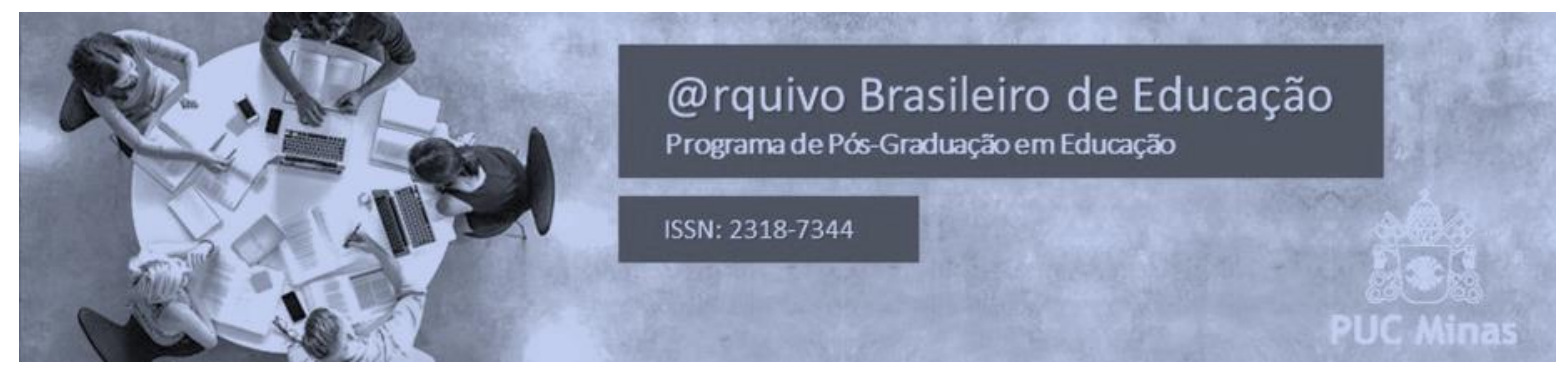

\title{
OS DIREITOS DAS CRIANÇAS E DOS ADOLESCENTES: UMA BREVE DISCUSSÃO
}

\section{CHILDREN AND ADOLESCENT RIGHTS: A BRIEF DISCUSSION}

\section{RESUMO:}

Bruno Freitas Santos Faculdade Evangélica Cristo Rei

$\mathrm{O}$ artigo tem como objetivo analisar a importância dos direitos das crianças e adolescentes dentro e fora do contexto escolar. Assim, buscou-se verificar quais são as melhores estratégias para amenizar as diversas situações, em que parte dos direitos das crianças e adolescentes são negados e negligenciados. Para a realização do artigo, buscou-se respaldos em autores como :Cortelazzo (2000), Waldron e Ruane (2011), Amartya Sen (2004) que traz à tona essa importante discussão, bem como os inúmeros problemas, que são gerados quando esses direitos não são repassados da forma de tantas situações problemas, que hoje são situações desumana, que deve ser combatidas com rigor e em caráter emergencial. $\mathrm{O}$ tipo de pesquisa que foi adotada é a pesquisa bibliográfica, na qual consiste em uma revisão de literatura, analisando os pontos convergentes e divergentes da temática. Assim, conclusões que o estudo chegou é que há muito a ser feito na forma de ações e intervenções, acompanhadas de políticas públicas para assegurar tais direitos.

Palavras-chaves: Crianças. Adolescentes. Escola. Família. Sociedade.

\section{ABSTRACT:}

The article aims to analyze the importance of the rights of children and adolescents inside and outside the school context. Thus, we sought to verify which are the best strategies to mitigate the different situations, in which part of the rights of children and adolescents are denied and neglected. For the realization of the article, we sought support from authors such as: Cortelazzo (2000), Waldron and Ruane (2011), Amartya Sen (2004) that brings up this important discussion, as well as the countless problems, that are generated when these rights are not passed on in the form of so many problem situations, which today are inhuman situations, which must be combated rigorously and in an emergency. The type of research that was adopted is bibliographic research, which consists of a literature review, analyzing the convergent and divergent points of the theme. Thus, conclusions that the study reached is that there is much to be done in the form of actions and interventions, accompanied by public policies to ensure such rights.

Keywords: Children. Teenagers. School. Family. Society. 


\section{INTRODUÇÃO}

A reflexão em torno das questões dos direitos das crianças e adolescentes, tem sido algo preocupante e ao mesmo tempo necessário. Inúmeras ações e intervenções ainda precisam ser realizadas para amenizar os problemas das inúmeras desigualdades das mais diversas naturezas e das múltiplas negligências, que são cometidas a cada instante no Brasil e no mundo, pois o número de crianças e adolescentes, que tem seus direitos roubados e negligenciados de alguma forma é assustador. Diferentemente do que diz SARLET (2002), através da Constituição Federal de 1988 em concordância com o Estatuto da Criança e do Adolescente na Lei $n^{0}$ 8.069/90), onde prevê teoricamente que o Estado tem a obrigação de proteger as crianças, no que se refere o cumprimento de seus direitos básicos como a educação básica, que hoje infelizmente na sociedade capitalista, virou uma mercadoria a ser comercializada na atualidade ( MANACORDA, 2007).

Sendo necessário inúmeras políticas públicas educacionais em prol da efetivação dos direitos como a educação, saúde, segurança, alimentação e moradia. Porque existem desde, que o mundo é mundo uma luta de classes, onde há uma separação de classe dominantes e classe dominante. Tais lutas são históricas e pertencem a nossa atualidade e as diferentes realidade.

Vivemos em uma sociedade alicerçada em um sistema capitalista, onde a força do capital é a prioridade daqueles que de alguma forma detém o poder, onde cada vez mais é difícil assegurar os direitos a todos, pois existe a lei do capitalismo, onde a sociedade também capitalista é sempre movida por aqueles, que tem maior poder financeiro, menosprezando e excluindo aqueles, que não dispõem de poderes financeiros, a isso dá se o nome de desigualdades sociais e econômicas. Além do descontrole do crescimento de natalidade, que torna a situação-problema em muitas das vezes insustentável.

A vida cotidiana com suas muitas agitações não, nos permitem que percebamos, o quanto somos lesados, roubados e vítimas das negligências nos mínimos detalhes de pequenos direitos, que vão desde uma pequena fila, que pegamos para resolver situações do cotidiano, até aqueles direitos mais gritantes.

Nas injustiças e nas muitas negligências da vida presente, muitos acabam se acomodando em uma vida sem os direitos, que lhes são inafiançáveis. Problemas dessa 
natureza, são cada vez mais comuns, nesse mundo de muitas injustiças e atrocidades, no que se refere aos direitos humanos e sociais, que são assegurados ou melhor dizendo citados em tantos documentos oficiais.

Para amenizar tais situações problemas é imprescindível, que haja uma consciência sobre quais são esses direitos e busca pela efetivação dos mesmos.

Reconhecendo também, que parte desses problemas, se dá pela prática de muitos crimes de corrupções e de impunidades, que estamos acostumados a respirar dia a após dia. Logicamente, que não se resolve da noite para o dia, os problemas que são históricos, mas há muito a ser feito em prol de uma sociedade mais equitativa e humana. Como confirma CHUNG, (2012), que diz que são muitos os motivos que levam o fracasso da educação e a negação de direitos básicos, tais como, falta de interesse pela escola pública por parte dos próprios órgãos competentes, que na grande maioria das vezes mascaram e camuflam os problemas.

A educação é um o direito básico e fundamental a todos, e é necessária para uma vida plena do sujeito, quando se trata de uma formação omnilateral, ou seja, em todas as dimensões. Assim, criar e desenvolver estratégias, na forma de políticas pública sociais para garantir a efetivação do direitos é de fundamental importância.

$\mathrm{O}$ artigo traz os resultados iniciais de uma pesquisa bibliográfica, que buscou analisar a importância dos direitos das crianças e adolescentes dentro e fora do contexto escolar, que precisam ser cuidadosamente repassados a todas as crianças e adolescentes. Diante do exposto, a situação problema que nortearam este trabalho foram as seguintes: Como combater os crimes de corrupção e de impunidade, que impedem o repasse de muitos direitos básicos as crianças e adolescentes? Que recursos podem ser usados para obter uma sociedade mais equitativa? Que estratégias são mais eficazes para assegurar os direitos mais básicos na prática e não em meramente documentos oficiais?

Assim, o objetivo do presente artigo é analisar a relevância da efetivação dos direitos humanos e sociais. A justificativa, que impulsionou a elaboração desse artigo é a busca por ações, que tornem os direitos mais acessíveis a todas as crianças e adolescentes

A estrutura desse trabalho se dá por meio de uma apresentação dos posicionamento de alguns teóricos, acerca dos diferentes tipos de direitos, que são necessário a todos, independentemente da cor, da religião, da classe social e da 
condição financeiras. Como confirma Brandão (2013) a educação tem uma infinita capacidade de criar e de recriam, entre tantas outras invenções da humanidade.

\section{METODOLOGIA}

Conforme foi apresentado na introdução, a pesquisa é de cunho bibliográfico, na qual teve como analisar a importância dos direitos das crianças e adolescentes dentro e fora do contexto escolar, frente a sua formação e construção enquanto pessoas e cidadãos. Trata-se de uma pesquisa também com o caráter qualitativa, realizada no período de trinta dias, onde foram levantadas diferentes posicionamentos acerca da manutenção e da efetivação dos direitos sociais e educacionais, mostrando seus muitos conceitos, bem como os prejuízos, que muitos sofrem frente as necessidade de direitos tão básicos, e que de alguma forma são negados de forma cruel e desumana. Quanto a análise dos dados coletados, foram colhidas informações pertinentes, para melhor fundamentar a pesquisa.

\section{DISCUTINDO MELHOR A TEMÁTICA}

Toda e qualquer criança e adolescente são sujeito protagonistas no processo educacional, sendo sujeitos ativos na formação e na construção da cidadania. Dessa forma são necessários, que alguns direitos na forma de proteção, segurança, alimentação, liberdade, educação, moradia sejam garantidos e assistidos não só em documentos oficiais, mas sim nas inúmeras realidades.

Assim, os setores da sociedade como o Estado, o Mercado, a Sociedade Civil e as ONGs são agentes importantes na efetividade dos direitos da criança e do adolescente, sendo necessário, que cada um deles exerça suas respectivas funções. É imprescindível, que sejam diferenciados quais são os conceitos básicos, no que se refere aos direitos das crianças e adolescentes e seus significados bem como suas respectivas funções. $\mathrm{O}$ Estado e a sociedade civil em muitas ocasiões se fundem, assim, sociedade civil e Estado, exercem um conceito dualista, que está em constante processo.

Os atores sociais desempenham um papel importantíssimo no processo educacional. E um desses papeis é ofertar a proteção as nossas crianças e adolescentes. A sociedade civil em especialmente as famílias, exercem uma tamanha 
responsabilidade na educação familiar e na escolar, com já está previsto na própria Constituição Federal de 1988.

No processo educacional, cada ator social, desempenha um papel primordial na construção dos diferentes saberes. A sociedade civil, as famílias, os professores tem um papel decisivo em torno dos resultados das escolas públicas. Assim, consolidar uma educação integral para as crianças e adolescentes é um direito, que não pode ser negligenciado em hipótese alguma. Cada ator social desempenha uma ação imprescindível dentro do processo de construção de saberes. Em concordância a tudo isso Anderson (2008), explica que o bem-estar da sociedade é de alguma forma garantidos por meio das políticas sociais públicas. O mesmo ainda, explica que os principais atores do processo precisam estar se reorganizando em prol de melhorias. E tudo isso funcionam com uma grande engrenagem, quando há deficiência em algumas dessas partes o produto final, sofre prejuízos.

Um dos segredos para se alcançar o sucesso na escola pública é o desenvolvimento de projetos socioeducativos de forma contínua, com participação social de todos os atores diretamente e indiretamente, envolvidos dentro do processo educativo. E para Feitosa (2000) o segredo para a qualidade educacional é a dedicação, uma palavra chave que é válida para tudo em sociedade. $\mathrm{E}$ isso exige sofrimentos e esforços mútuos. Assim, as políticas públicas são imprescindível para consolidar a educação integral para crianças, adolescentes e jovens brasileiros em condições de vulnerabilidade socioeconômica, com as taxas elevadas e preocupantes.

A participação da sociedade civil no campo da educação, acontece de diversos modos, e essa participação deve ser contínua e permanente. A educação familiar e escolar é um direito previsto em lei. Dessa forma, a obrigação de cada agente é necessário, pois se alguma das partes se omitirem ou falhares, todo o processo fica comprometido. O ato de educar os filhos, não é uma tarefa de poucos, mas sim de todos os demais envolvidos dentro do processo escolar, e isso é sempre crescente e contínuo.

O Código Civil estabelece a guarda e a proteção da saúde física e psicológica e a educação integral dos seus filhos. ( $§ 5^{\circ}$ do Art. 1.583 - Art. 1.589 e Art. 1.694). Assim os direitos, são muitos a serem minunciosamente exercidos, o desafio maior é fazê-los acontecer na prática, em meio a tantas obstáculos e desigualdades que impedem o seu cumprimento. 
O Código Penal, por sua vez, no art. 246, prevê o crime de abandono intelectual, muito comum ainda no Brasil: "Deixar, sem justa causa, de prover à instrução primária de filho em idade escolar". É um grave problema ainda muito comum no Brasil, que deve ser cuidadosamente denunciado e punido. E pela própria legislação é estabelecido pena de detenção, de quinze dias a um mês, ou multa para quem praticar essa conduta. Lamentavelmente ainda, existe um grande número de pais omissos, acerca desse direito, que é inegável as nossas crianças e adolescentes. Sem falar o número de crianças e adolescentes em orfanatos. Que de acordo com dados do IBGE (2017) o Brasil tem 47 mil crianças em abrigos, e na fila de adoção tem 6,5 mil crianças e adolescentes no Brasil. E os grandes inimigos de tudo isso se chama burocracia e lentos trâmites judiciais, que fazem com que meninos e meninas demorem para encontrar uma família, um direito tão básico e tão vital a todos.

O direito e o dever dos pais de atuar na educação de seus filhos é imprescindível, porém ainda existe muita negligências nesse sentido, e um deles é a imaturidade na hora de exercer a função de pais. A pesquisa "Atitudes pela Educação", divulgada em 2014 pelo movimento Todos Pela Educação, mostrou que ainda é muito pequeno o número de pais participativos em torno de $12 \%$ dos pais são responsáveis e realmente comprometidos com vida escolar das crianças, adolescentes e jovens.

Esse percentual é representado por aqueles indivíduos, que realmente buscam informações sobre a escola, promovem o diálogo e a parceria com outros pais e professores, acompanham e apoiam os filhos na rotina escolar. Dessa forma é necessário articular ações de conscientização para que esse número cresça significantemente. O Código Civil, no inciso IV do art. 1.566, estabelece que são deveres de ambos os cônjuges "sustento, guarda e educação dos filhos".

Essa lei estabelece ainda no art.1.568 que: Os cônjuges são obrigados a concorrer, na proporção de seus bens e dos rendimentos do trabalho, para o sustento da família e a educação dos filhos, qualquer que seja o regime patrimonial. Assim, há muito a ainda a ser feito em prol da aquisição de tantos direitos, que são básicos e ao mesmo tempo necessários a todos.

\section{A LDB COMO MARCO DE PROTEÇÃO DAS CRIANÇAS.}


Garantir a proteção das crianças, adolescentes e jovens é um direito previsto em lei. Assim, a LDB é um grande marco jurídico mais importante da área educacional e fundamental para garantir educação. No entanto surge a indagação: Ela realmente tem funcionado na prática A Lei de Diretrizes e Bases da Educação Nacional como é conhecida como a LDB é um documento com qual os educadores estejam mais familiarizados e a mesma está em concordância com outros importantes documentos como o Plano Nacional de Educação. A trajetória da Lei de Diretrizes e Bases da Educação Nacional - LDB, desde a primeira sanção, em 1961 (lei no 4.024/61) à última, em 1996, (lei nº 9.394/96) trouxe grandes conquistas para a educação em todas as instâncias. Todas essas leis e decretos desempenham o papel de orientar e dar diretrizes para uma educação muito promissora. O desejo de uma educação significativa e ampla é um sonho que é possível para todos os cidadãos, se cada dê suas parcelas de contribuições, isso se de fato se tornará uma realidade.

A democracia na educação é um dos principais caminhos para efetivar uma educação integral e plena para todos as crianças, adolescentes e jovens. A democracia começa com uma gestão democrática participativa, e isso é uma grande conquista, que mudou o panorama histórico, político e social do Brasil, desde o fim da ditadura militar no Brasil na década de 1980. E para Saviani (1999) é possível perceber como essa lei configurou soluções intermediária para inúmeros problemas educacionais.

Uma educação com gestão e com democracia participativa é ainda um desafio a ser superado a cada dia. Porque nas palavras, tudo isso soa muito bem aos ouvidos. Por outro lado, a prática revela muitas contrariedades, que requer ações e intervenções nas mais diversas áreas. Construir paulatinamente uma sociedade livre, justa e solidária; Erradicar a pobreza e a marginalização e reduzir as desigualdades sociais e regionais; Promover o bem de todos, sem preconceitos de origem, raça, sexo, cor, idade e quaisquer outras formas de discriminação. (CONSTITUIÇÃO FEDERAL, 1988). Todo esse contexto, citado acima significa muito, e sem dúvida alguma possui uma grande amplitude. No entanto, fazer cumprir na prática tudo isso, exige uma série de ações e intervenções, que vão desde as mais simples, até as mais complexas. E tudo isso é uma engrenagem, que não depende apenas de bons discursos ou de boas intenções, e sim de ações reais.

Muitos são os passos a serem dados em prol de uma educação com maior efetividade. Na visão de Mccowan (2013) a educação é um direito humano, e tais 
direitos são fundamental a todos. E o reconhecimento dos mesmos, precisam ser cumprido na prática, tal como a proteção desses direitos que são individuais, civis e políticos. E tais direitos são de todos e para todos, sem distinção alguma, seja ela social, econômica, etnia, religiosa, mesmo estando inseridos em uma sociedade excludente.

Tratar dos direitos humanos, escolares, familiares, civis é muito complexo e amplo. Todo e qualquer cidadão deve assumir a postura de defensores dos direitos da área da Educação. Uma vez, que todos tem nas mãos o poder de educar, disciplinar e corrigir, mesmo que muitos não percebam toda essa capacidade.

É preciso entender o significado e a funções dos direitos, sendo que os mesmo é fruto de muitas lutas políticas e civis, que custou, o suor e sangue, a liberdade e a vida de muitos. Os direitos são fundamentais a todos, e nós brasileiros temos o privilégio de viver em um Estado democrático de direito, e isso é algo relevante em relação aos que vivem em países onde a ditadura ainda prevalece, por meio do poder coercitivo.

Todos, temos uma certa noção a respeito do que é o Estado? E do que é direito? Tem se uma ideia de que existem legislações nacionais e internacionais que garantem os direitos da criança e do adolescente especialmente na área de educação. Por outro lado é preciso ampliar esse entendimento, obtendo maior profundidade, acerca da temática. Porque quanto mais sabemos, melhor é para intervir nas realidades sociais.

É importante pensar por exemplo, nas seguintes questões Como o estado e o direito se constitui historicamente? Quais as suas principais funções? Qual é a história de abrangência dos Direitos Humanos? Qual é o papel do estado democrático de direito? Quais as funções de suas instituições da efetivação do direito à educação? Todas essas indagações e as suas respostas, são essenciais para que haja uma melhor compreensão da realidade para o melhor exercício de nossa atividade profissional. Evitando o problema que Pereira (2006), explica chamando de esvaziamento dos direitos de cidadania, a privatização de alguns direitos e a quebra da garantia dos mesmos direitos.

Todos e qualquer ser humano estão vinculados direta ou indiretamente ao universo jurídico, o que quebra o tabu criado ao longo dos anos, de que a ideia de direitos pertencem apenas aos profissionais, que atuam na justiça. O conhecimento desses conceitos contribuem para a construção de uma sociedade mais livre justa e solidária. 
As organizações da sociedade civil e da educação estão todas embasadas em direitos e deveres. Dessa forma associações, fundações, ONG, organizações não governamentais trabalham e exercem suas funções em prol da garantia e da assistência dos direitos de todos. Então, é importante diferenciar o que cada uma dessas siglas e desses nomes tem, e o papel de cada uma delas em determinado setores da sociedade.

Há ainda muita desinformação, acerca de quais são os direitos e quais são os deveres de cada um dentro da sociedade. Todos, sem exceção alguma precisar ser agentes ativos e participativos das organizações da sociedade civil. Para Amartya Sen (2004) os direitos são essencialmente morais, e sua consagração em lei é um processo secundário, que precisa ser preservado em todas as instâncias.

Os direitos da criança e do adolescente ao longo dos anos são conquistas significativas e também uma construção histórica, que é motivo de alegria em meio a tantos problemas, que em tempo remotos sofriam sem usufruir, tais direitos, tendo sua infância roubada e negligenciada por fatores e situações. E em concordância a tudo isso Sem (2004) compara os direitos como mecanismos essenciais para proteger a humanidade contra os abusos dos direitos, uma prática que infelizmente é ainda muito comum no Brasil e no mundo. A questão é que para validar tais direitos, exigem o rompimento de várias barreiras das mais diversas naturezas, e isso requer uma série de ações em conjunto, e que tem um alto custo, mas que é preciso.

Ao falar de direitos e deveres das crianças e adolescentes, não se pode descartar em hipótese alguma, o descaso dos órgãos públicos com tudo aquilo que é público. $\mathrm{E}$ que, a partir dela surgem os seguimentos como as constituições estaduais e municipais.

E para melhor fundamentar, isso Mccowan (2013) os direitos servem de apoio mútuo para as diversas situações da vida humano, dando um sentido e uma compreensão progressiva. No mundo dos direitos eles dão maior capacidade de agir, pensar e modificar nossas diferentes realidades.

Vale ressaltar, que os direitos se dividem em dois importantes momentos. Para Waldron e Ruane (2011) o primeiro é o direito interno e as normas de direito internacional, são aplicáveis ao Brasil e ao todos os demais países. Os tratados internacionais e nacionais são leis criadas para beneficiar, um determinado público e combater uma determinada situação problema, que ao observar o contexto presente, são inúmeras. 
No Brasil quando se fala de leis brasileiras, acerca dos direitos e dos deveres das crianças e adolescentes, o maior problema encontrado é o não cumprimento dessas leis. Dessa forma, conhecer quais são as principais normas internacionais de proteção à criança e ao adolescente é de suma importância.

A Constituição Federal é um marco jurídico voltado para garantir a proteção. E dentro da CF de 1988, surge o ECA como uma forma de assegurar e garantir ainda mais que a educação da criança e do adolescente na idade certa, bem como a proteção da integralidade física de moral do sujeito.

Por fim, a Constituição Federal é a lei maior de qualquer país democrático, e isso significa que a mesma devem estar em harmonia com as demais leis que são subconsequentes da própria Constituição Federal. A Constituição Federal tem muitas características, e em especial ela não estabelece apenas direitos e deveres, mas também determina as diretrizes políticas a serem seguidas tais como construir uma sociedade livre e solidária. Erradicar a pobreza e a marginalização e reduzir as desigualdades sociais e regionais, promover o bem de todos sem preconceitos de origem raça sexo cor idade e quaisquer outras formas de discriminação. São necessárias a toda sociedade, mas ao mesmo tempo desafiadoras.

Todas essas diretrizes tem objetivos fundamentais dentro da República Federativa do Brasil, conforme o artigo terceiro da Constituição Federal atuar na área da educação é uma das formas mais efetivas de alcançar os objetivos estabelecidos na própria constituição.

Assim, a educação aparece como um direito básico de todos os cidadãos, pois é por meio dela e através dela, que de estabelece diretrizes e princípios para toda uma vida, assim ela ganha importância e valor. Assegurar o direito à educação é um grande desafio a ser superado. De acordo com a UNESCO (2018) cerca de 263 milhões de crianças e adolescentes estão fora de escola, dados também apontam que países pobres e com baixa renda, a taxa de evasão de estudantes de 15 a 17 anos é maior. Por último, a UNESCO (2018) diz que 1 em cada 5 crianças e adolescentes está fora da escola.

A Constituição enfrenta enormes desafios para consolidar uma educação plena, integral no Brasil. Uma educação efetiva é indispensável para forma um indivíduo pleno e completo. Porém a busca por tais direitos, pode ser muitas das vezes motivos para ameaças, represálias e muitos outros tipo de violência, como confirma Bajaj (2011) em seus estudos. 


\section{ECONOMIA DE MERCADO E EDUCAÇÃO}

Ao falar de direitos e deveres da criança e do adolescente, envolve outros assuntos que são protagonistas e outros que são coadjuvantes. Os desafios da educação são gigantescos, e todos esses desafios são também desafios de natureza política e econômica. Para a Declaração Universal dos Direitos Humanos, (1948) todos precisam alcançar o pleno desenvolvimento da personalidade humana e do fortalecimento do respeito pelos direitos humanos e pelas liberdades. Sendo que, o direito à aprendizagem é considerado um direitos humanos. No entanto, a intolerância e a negligência tem sido grande barreiras na efetivação desses direitos.

Segundo o relatório do UNICEF (2015), os países de baixa renda é ainda preocupante, pois ainda existe a concentração de muitas populações vivendo na pobreza extrema e em condições de inúmeras desvantagens, negligenciados de forma desumana e cruel, tendo muitos dos seus direitos roubado.

As crianças pobres de acordo com a UNICEF (2015), vivem agora em países de renda média, ou seja, a maioria das crianças pobres estão em países marcados pelas maiores desigualdades de renda, este é o caso do Brasil. Ainda, segundo o relatório da UNICEF no mundo, uma em cada 10 crianças em idade escolar, não frequentam a escola entre os adolescentes.

Este número ainda, diz que 1 em cada cinco adolescentes não frequentam a escola e existe uma correlação direta relação com a pobreza. Mas existe também notícias boas, que servem de estímulo e de encorajamento. Dados apresentados diz, que a matrícula na escola primária aumentou significantemente. Em relação aos dados estatísticos dos anos 90, que diz que apenas 53 em cada 100 crianças desses países tiveram acesso a escola.

Muitos são os problemas identificados na educação de diferentes naturezas, mas que existe soluções em meio aos problemas enfrentados. Para melhorar a educação em nosso país combater a desigualdade social e todas as formas de preconceito e discriminação são imprescindíveis para garantir um melhor futuro para todas as crianças, adolescentes e jovens. E na concepção de Osler e Starkey (2010), a educação além de ser um direito humano é a capacidade de promover o pensamento crítico, e tal pensamento crítico é a luta incessante por justiça. 
Nesse sentido governo, Ong, as empresas, sociedade civil, escola e famílias desempenham um papel fundamental, na reconstrução e construção de uma nova educação, muito mais plena e significativa. Iniciativas, ações e estratégias são armas poderosas para transformar passivamente a educação de hoje para uma futuro promissor. Assim, a educação é sempre motivadora, precisa de reflexões, ações, estratégias eficazes para uma educação de todos e para todos.

Um dos muitos obstáculos, que impedem que direitos básicos sejam contemplados por todos, estão intimamente relacionados com as questões econômicas do país. Dessa forma, atualmente no Brasil, a baixa renda familiar ainda é o principal fator, que define o analfabetismo e a continuidade da permanência do indivíduo na escola. Muitas famílias, que recebem até um quarto de salário mínimo por mês apresentam 20 vezes mais analfabetos em relação as demais famílias, que recebem um salário completo. Assim, investir nos aspectos da economia brasileira é investir na educação como um todo. Uma vez que, a educação caminha em concordância com muitos outros aspectos.

De acordo com dado do IPEA (2010) Instituto de Pesquisa Econômica Aplicada (IPEA), mostra que 93\% dos analfabetos ganham menos de dois salários mínimos. E que a má e a baixa distribuição de renda é um impacto negativo para a excelência do desenvolvimento educacional do país por ns questões. Muito já, foi investido nas questões referentes ao analfabetismo, porém há muito ainda ser feito. Porque o baixo grau de instrução está relacionado com as questões econômicas. Então, tais problemas dessa natureza limita consideravelmente as possibilidades do alcance e do usufruir de direitos básico como o de ser alfabetizado.

O relatório do movimento Todos pela Educação indicava que no Brasil, em 2013, 93,6\%das crianças e dos jovens entre 4 e 17 anos estavam na escola. Isso revela o que chamamos de exclusão social, um grave problema que precisa ser cuidadosamente intervindo por meio de políticas públicas ativas e permanentes, com o intuito de garantir e de fazer valer os direitos de todos. A educação um elemento tão básico, que é o acesso e a permanência de crianças e adolescentes dentro do ambiente escolar.

\section{IMPACTOS DA DESIGUALDADE DE RENDA NA EDUCAÇÃO}


Os impactos das inúmeras desigualdades de renda no país, afeta negativamente os avanços da educação, sendo uma grande pedra de tropeço, que impedem o desenvolvimento exitoso da educação em várias instâncias. Dados recente diz, que cerca de 9 em cada 10 crianças frequentam a escola primária. E o que acontece com essa as demais, que não aparecem inclusas dentro do sistema educacional? A resposta é simples, estão as margens da exclusão social. E na visão de Abramowicz, Rodrigues, Cruz (2011), enquanto não for combatida, amenizada e intervinda essas diferenças as desigualdades na educação será um grande obstáculo.

A educação em todo o mundo, sofre inúmeros prejuízos e defasagem, a exemplo disso é a África central e ocidental, para cada cem meninos matriculados na escola primária são admitidas apenas 90 meninas. O nível de exclusão é mais grave para a escola secundária, onde há apenas 76 meninas matriculadas para cada cem meninos. Isso revela uma sociedade machista e preconceituosa, que ainda enxergam a figura da mulher de forma excludente e discrimatória.

Já em território nacional, o Brasil permanece como um dos países mais desiguais do mundo, conforme Relatório de Desenvolvimento Humano (2015) da ONU. E ao se falar de desigualdade, falamos também da omissão do cumprimento de direitos básicos a esses cidadãos. Tais desigualdades, se revelam na forma de desigualdades econômicas, as diversas formas de preconceito e discriminação especialmente ligadas a gênero, raça/etnia, nacionalidade, orientação sexual e deficiência contribuem para a perpetuação de um cenário de injustiça social e assimetria de oportunidades. No ambiente escolar, o combate e prevenção dessas práticas são essenciais, para construirmos um futuro promissor e exitoso para as crianças e adolescentes de hoje, que serão os adultos do futuro.

Nesse contexto, torna-se imprescindível o engajamento e a participação de todos os agentes as empresas junto ao poder público, escola e sociedade civil para financiar, apoiar e executar ações e iniciativas voltadas para o desenvolvimento pleno de todos os seres humanos por meio da educação. Então, já se sabe, que um dos eixos fundamentais para o combate às desigualdades sociais é a educação. E quanto a isso é algo indiscutível. E tudo deve se começar pela família que é o primeiro núcleo social que abriga o homem. É ela quem vai dar condições à criança, ao adolescente e ao jovem de construir seus modelos, de aprender e fazer. 
A legislação brasileira possui uma série de regulamentos, decretos, incisos e artigos referentes aos direitos e deveres. No entanto, falta o devido rigor para aplicar na prática todos esses direitos. A educação é sempre sinônimo de pluralidade, sendo um fator decisivo para aumentar as oportunidades de emprego, renda desenvolvimento em todos os aspectos.

Hoje, há inúmeras situações a serem encaradas e vencidas, quando se fala de direito e deveres das crianças e adolescentes, um deles é inserir dentro dos espaços de aprendizagem, as crianças e adolescente que por ns fatores se encontram excluídos e o segundo é a permanência dos mesmos dentro das instituições de ensino.

\section{ORGANIZAÇÃO DO ESTADO CONTEMPORÂNEO.}

Por diversas vezes, ouve-se muito a frase poética de que o Brasil é um estado livre e de direito. E isso, é sem sombras de dúvidas uma grande e significativa conquista. O Brasil é um estado livre e de direito, sendo uma grandiosa conquista, no que se refere aos direitos dos cidadãos. Os poderes executivos, legislativos e judiciários a nível federal, estadual e municipal desempenham um papel primordial para assegurar e garantir os direitos básicos para toda uma sociedade (RODRIGUES ; NUNES, 2010).

As atividades educacionais está vinculada direta e indiretamente com a participação de todos, e se tratando dos direitos à educação todos os diversos atores envolvidos tais como as famílias, estudantes, professores, Ongs, governos, comunidade são capazes de revolucionar positivamente a área educacional. Dessa forma é preciso conhecer as instituições e a função que cada um desempenha, distinguir os três conceitos fundamentais entre estado, governo e políticas públicas é necessário para agir e articular ações.

O Estado exerce um papel de suma importância, no que se refere aos direitos da educação. Nesse sentido os quatro elementos do estado: A soberania, o território, o povo e a finalidade. Tem grande relevância na hora de formular e reformular definições para um futuro promissor. Nessa linha de reflexão, Marcos Pereira (2014) explica que a instituição-escola é o lócus, por excelência, onde ocorre a apropriação e a (re) construção de conhecimentos e de transformações, e cabe ao estado propiciar tudo isso (PLANETA EDUCAÇÃO, 2014) 
Para melhor definição sobre o que é Estado, ele se define como uma corporação de um povo, assentada num determinado território e detentora de um poder originário de mando. Num segundo momento o Estado é também a ordem jurídica soberana, que tem por fim, o bem comum de um povo situado em um determinado território. Numa terceira instância o Estado é um produto histórico, e por essa razão há um processo político, que faz surgir diversas instituições que trabalham em parceria com o estado, tais como o Ministério Público, o Poder Judiciário, agências reguladoras, órgãos da administração pública direta etc.

Assim, uma educação equitativa é aquela de todos e para todos, e isso se faz com a parceria de todos esses órgãos aqui citados. E para Sousa (2010) a obrigatoriedade de tudo isso é do estado, que exerce uma função social relevante e imprescindível, quando se fala de educação democrática e dos direitos civis.

Não se pode esquecer, que as agências reguladoras, desempenham uma papel grandioso, no que se refere aos direitos educacionais das crianças e adolescentes. Vale ressaltar, que elas foram criadas para fiscalizar a prestação de serviços públicos praticados pela iniciativa privada, que também é responsável pela educação como um direito, além que seja para poucos. As agencias reguladora controlam a qualidade na prestação do serviço, estabelecem regras para o setor. Atualmente, existem dez agências reguladoras.

A regulação envolve medidas e ações do Governo, que envolvem a criação de normas, o controle e a fiscalização de segmentos de mercado explorados por empresas para assegurar o interesse público. De acordo com o Portal Brasil são exemplos de agências reguladora: Agência Nacional de Telecomunicações (Anatel); Agência Nacional do Petróleo, Gás Natural e Biocombustíveis (ANP); Agência Nacional de Energia Elétrica (Aneel);

A conquista do Estado brasileiro com uma República Federativa é de suma importância para todos os brasileiros, uma vez que no passado, antes de se tornar uma república os índices de exclusão eram gigantescos. E nos estudos de Vieira (2010), é descrito com maior ênfase as fases históricas do Brasil como Estado de Direito, mostrando pontos relentes dessa importante linha do tempo. Dessa forma a república federativa é formado por quatro tipos de entes federados, são eles: União, Distrito Federal (Brasília), estados e municípios. 
Cada ente federado possui sua autonomia financeira, política e administrativa. Dessa forma, os entes federados são independentes uns dos outros, não havendo hierarquia ente eles. O Estado é o ordenamento jurídico soberano de um povo em um determinado território. $\mathrm{E}$ isso, deve funcionar também na prática para que tais direitos não sejam negados e nem muito menos negligenciados.

O governo é composto de representantes políticos, agentes administrativos (concursados ou nomeados), estando incumbido de exercer a administração pública conjuntamente com a colaboração de indivíduos e organizações da sociedade civil. Porém, nessa classificação citada acima, existe os inúmeros crimes de corrupção, que acontece nos diferentes setores, e que na grande maioria das vezes, ficam impunes, sem as devidas correções.

As políticas públicas são importantes ações e decisões decorrentes do governo, do Estado, da escola, da família. Tais medidas são estabelecidas a partir de planos, projetos e metas e devem estar voltadas para atender às demandas sociais em diversos âmbitos na educação, saúde, esporte etc. No entanto, precisam ser ampliadas e direcionadas para cada situação problema, que são ns fatores. E para Oliveira, (2010) as "políticas públicas" é tudo aquilo, que um governo faz em prol de um bem comum da sua população.

O governo, dentre outras atribuições, mobiliza as instituições estatais (federais, estatais ou municipais) para promover políticas públicas, que precisam ser direcionadas de forma contínua e permanente. Os direitos humanos abrangem os direitos a educação, que possibilitam o desenvolvimento da pessoa, como cidadão que deve ser formado em sua plenitude. A educação é um direito de todos e um dever do Estado e da família, porém tem sido negligenciados a muitos. É indispensável, que a escola sejam um ambiente democrático, inclusivo e transformador. Dessa forma as políticas públicas na forma de projetos é uma excelente estratégia para a melhoria da educação no país.

\section{DIREITO DA PERSONALIDADE HUMANA}

É muito comum se ouvir a expressão direitos da personalidade humana. Mas o que seria de fato esse termo? De forma simplificada é um termo técnico, que reforça a 
ideia dos direitos, que cada sujeito tem em ter uma identidade própria, uma personalidade humana.

Essa expressão significa, também a proteção do indivíduo. E ao observar esse contexto, percebe as grandes dificuldades encontradas para fazer acontecer esse direito na prática, uma vez que a insegurança é um grave problema a ser intervindo. O direito a segurança física e moral do sujeito, não é fácil de ser assegurada, uma vez que os direitos previstos em lei estão distantes da realidade nas ruas, nas escolas, no bairro e em cada cidade. No artigo 52 do Código Civil, aplica-se à esse importante direito a todas as pessoas.

É papel do Estado assegurar a toda sociedade e seus cidadãos, o direito a proteção e segurança como está previsto no Art. 205 a educação, direito de todos e dever do Estado e da família, será promovida e incentivada com a colaboração da sociedade. Por outro lado, tem si visto que o Estado tem falhado na efetivação dos direitos mais básicos como a educação e a segurança por meio do policiamento. A relação existente entre as leis teórica escrita em artigos, incisos e documentos oficiais, é ainda muito distante daquilo, que deveria ser.

As ações e as intervenções, até aqui realizadas são ainda insuficiente para a garantir proteção de todos, especialmente crianças e adolescentes em todo o país com enormes problemas de note a sul. Na grande maioria das vezes, esse problema se somam a uma série de outros problemas, que torna a efetivação dos nossos direitos, cada vez mais difíceis.

Segundo o Instituto Nacional de Estudos e Pesquisas Educacionais Anísio Teixeira - INEP (2017) um dos desafios essenciais para a efetivação de uma educação de qualidade, em nosso país, estaria relacionado no Produto Interno Bruto - PIB, que hoje investe, aproximadamente $5 \%$ com educação. Isso implica uma grande negligência e um grande descaso como um dos elementos chaves de toda uma nação que é a "educação".

\section{PARTICIPAÇÃO DA SOCIEDADE CIVIL NO CAMPO EDUCACIONAL}

Na efetivação e na concretização dos direitos das crianças e adolescentes, é indispensável a intensa e permanente participação da sociedade civil no campo 
educacional. Lamentavelmente tem se visto, que nem sempre isso tem ocorrido na frequência e na intensidade em que deve ocorrer.

Na visão de Garcia (2006) a parceria entre a família e a escola é de suma importância para o sucesso no desenvolvimento intelectual, moral e na formação dos indivíduos. Infelizmente ainda falta uma participação significante das famílias na escola, e na vida escolar de seus filhos.

A participação da sociedade civil no campo educacional é ainda um problema comum, pois a falta de atrativos e da negligencia da comunidade escolar, é um grave problema a ser intervindo de formas sabia e emergencial, pois a educação é um dever de todos, e não de uma minoria. O Brasil é um estado democrático de direito isso está estabelecida em nossa Constituição Federal, no entanto a democracia, tão falada e discutida tem ficado preso muito nas teorias, ao invés da prática do dia a dia.

A Constituição Federal(1988) estabelece, que todo poder emana do povo, porém a realidade é que o povo tem sido manobrado e manipulado nas mãos de governos corruptos e desumanos, onde parte dos direitos de crianças adolescentes tem ficado só em palavras ao vento. Falta maior fiscalização de direitos toa essenciais e necessários a todos nós, e o fazer valer de todos eles de forma real.

Infelizmente as leis ainda são muito abstrata, mas é um princípio que orienta todo o ordenamento jurídico, a partir desse princípio diversas leis são feitas para garantir o usufruir dos direitos básicos. A participação e a interação entre o poder público e a sociedade civil é uma dobradinha, que deve existir em todas as instancias, pois sem elas todos os resultados da educação e dos demais seguimentos de uma sociedade fica comprometido. E em concordância a tudo isso Cortelazzo, (2000) fala que as instituições, famíliar e escolar se complementar no intuito de alcançar um objetivo cada vez maior que é a formação integral da criança e dos adolescentes.

Vale lembrar, que o aperfeiçoamento da democracia e da sociedade se dá a partir da participação de todos junto aos poderes executivos, legislativo e judiciário. Acontecendo essa participação que é muito válida o Estado se torna ainda mais democrático e representativa dos interesses da coletividade. Além disso, as organizações existentes dentro da sociedade civil, se torna forte, quando há interesses comuns em busca de uma melhor educação, como um direito que não pode ser negado a ninguém. Afinal de contas, todos nós almejamos construir e consolidar uma sociedade mais plural e democrática para todos. 
A educação para ser de fato efetivada deve ser construída com o suporte de várias políticas educacionais. Dessa forma os políticos, que estão na gestão e nos diferentes poderes, exercem um papel fundamental nessa construção, pois em partes eles detém nas mãos o poder de consolidar e realizar inúmeras ações, que refletiram positivamente ou negativamente em todo o processo educacional. E ao observar os estudos de Canoy (2002) é mostrado os paliativos, que governos têm usado para mascarar a educação por meio de dados estatísticos, que nem sempre condiz om a realidade vivenciada. Dessa forma, de nada adianta, se não houver os investimentos e os recursos certos para efetivar os direitos a educação, moradia, alimentação etc.

Ao falar da palavra "direitos" das crianças e adolescentes, percebemos grandes conquistas e vitórias ao longo da história. Como diz Nunes, (1978) em sua obra a História da educação na antiguidade cristã, onde as crianças não eram vista como crianças e sim como adultos em miniaturas. Isso implica que do mundo antigo e para o contemporâneo, muitas conquistas, foram alcançadas. Ao analisar as sociedades prémodernas, as crianças não tinha infância, eram treinadas para o trabalho com cargas horarias de trabalho abusivas, como ocorreu na Revolução Industrial. Hoje existi o que chamamos de estado de direito, nem muito menos os direitos á infância, pelo contrário as crianças desde muito cedo, recebiam tarefas e responsabilidades como se já fossem adultos, sem a maturidade necessário para assimilar e absorver determinadas situações.

Isso ocorreu exatamente no século XV, um pouco mais de 500 anos atrás, época em que não existia o termo "criança" ou "infância" não existia. Naquela época, não havia um cuidado com a infância, um ciclo tão bel da vida humana. E durante essa época essas falas, eram muito comuns, foi ai que as mesmas, foram caracterizadas como seres estranhos, dos quais nada se sabe muito sobre elas. E hoje, já se sabe que elas são seres especiais, que precisam ser respeitadas e que precisam de tempo para crescerem e amadurecerem com afirma vários psicólogos Jeans Piaget, que traz todas as fases da crianças como etapas importantíssimas (LUZURIAGA,1984).

Por outro lado, na atualidade o Estado de direito vê as crianças como um sujeito em construção, e que cada fase deve ser vivida com naturalidade, sem sufocar com inúmeras tarefas ou responsabilidades, que eram direcionadas aos adultos. $\mathrm{O}$ modo de ver a vida social hoje é muito mais equilibrado e humano, do que nas sociedades 
antigas, como forma citadas aqui. Para Ghiraldelli (2002) faz referência a infância, como a fase da inocência

Respeitar as leis em vigor é indispensável, para se manter a ordem, a decências e o controle social. E mesmo assim, se vê as inúmeras injustiças nos diferentes aspectos da sociedade. Existem inúmeras ocasiões e situações, em que os direitos são negados e acabam provocando situações de flagrantes e de muitas injustiças. É nesses momentos, que percebemos que há uma tensão entre o estado e a efetivação dos direito, onde não há de fato a efetivação desses direitos.

Ao analisar a história, encontramos fatos curiosos e ao mesmo tempo desumanos. Por exemplo, haviam algumas civilizações em que, não havia sentimentos pela infância. E isso ocorreu mais precisadamente na sociedade medieval. E que volta e meia, acontece nos tempos presentes, pois existe crimes bárbaros cometidos a cada instantes contra nossas crianças e adolescentes. Porque de acordo com uma Pesquisa Nacional de Saúde do Escolar em parceria com o Atlas da violência (2016), tem se demonstrado um quadro dramático, onde crianças e adolescentes entre 13 e 15 anos já foram forçados a ter relação sexual, são chamadas estupro infantil. O percentual para meninos foi de $3,7 \%$ e para as meninas de 4,3\%. Além de outros crimes como negligencias, abandono ou desprezado

E ao observar as experiências históricas do século XX, mostrar que a simples existência de leis e governos não é condição suficiente para a construção de uma sociedade livre justa solidária e igualitária, bem como a consolidação dos direitos tão básicos a todos. Um dos maiores desafios na contemporaneidade é aumentar a legitimidade dos direitos humanos e sociais a todos, ou seja, a maior efetividade dos mesmos, independentemente da classe social, das questões econômicas, éticas ou religiosas dos indivíduos.

Assim, sendo quais são os obstáculos para sua efetivação dos direitos sociais as crianças e adolescentes. A resposta vem, por meio da justificativas de que as demandas sociais é imensa. No entanto, falta uma boa administração e repasse dos recursos públicos, para que tais direitos em hipótese alguma, sejam negados ou roubados de quem mais precisa.

Garantir os direitos as crianças e adolescentes é trabalhar a individualidade, e isso é um grande desafio que precisa ser superado pelo Estado, pela sociedade, pela escola e pelas as famílias. 
E ao falar da diversidade e da individualidade que precisa ser respeitadas, a arma mais poderosa para trabalhar tudo isso é a educação. Aliada, obviamente a um conjunto de outras ações na forma de políticas públicas nas áreas diversas em que essas crianças e adolescentes estão inseridos. Garantir os direitos é um ato de amor, e educação está diretamente ligado ao fortalecimento de vínculos, que tem grande valor na construção da identidade e da personalidade do sujeito.

Dessa forma, o Estado precisa ser cada vez mais, um ambiente mais democrático e mais participativo, encarando os desafios para a construção de um regime democrático, onde os direitos e deveres sejam cumpridos com maior eficácia e eficiência. Para melhorar a realidade política, social, educacional econômica existente, não é um tarefa fácil, e tais problemas impedem que os direitos sejam destinados e usufruídos por aqueles, que mais precisam e necessitam. No entanto, é possível construir paulatinamente um país melhor e de acesso equitativo para todos, onde haja a legitimidade do direito de todos e para todos.

Tratar da proteção jurídica de crianças e adolescentes é um grande desafio para todos, seja o Estado, a sociedade, a escola e a família. De acordo com um estudo da organização não governamental Save the Children (2016) a vida das crianças e adolescentes em todo o mundo melhorou consideravelmente nos últimos vinte anos. O Brasil, contudo, é um dos países, que registraram avanços mais positivos desde 2000.

Por outro lado o ranking de nações, que tem suas crianças e adolescentes desprotegidas é ainda alarmante, e inúmeras outras ações precisam ser articulas para que haja de fato proteção à criança com o um direito. E ao falar de Brasil, o mesmo se enquadra atualmente no grupo de países classificados pela ONG Save the Children (2016) como um país em que algumas crianças estão perdendo sua infância, vítimas de uma série de violências que as atinge.

O Estatuto da Criança e do Adolescente o ECA, fala com intensidade da questão da proteção as crianças. No entanto, é importante lembrar que a demanda populacional de crianças e adolescentes é uma grande barreira para garantir o direito a proteção, pois muitas dessas crianças e adolesceste sofrem uma serie de violências dentro dos próprios lares, por parte dos próprios familiares é a chamada violência doméstica interna. Há, várias leis que estabelece direitos e mecanismos de proteção às 
crianças e adolescentes, porém o cumprimento da mesmas é ainda um desafio a ser superado.

Existem, ainda como suporte para efetivar os direitos normas nacionais e internacionais voltados especialmente para o desenvolvimento de crianças e adolescentes em concordância com a Constituição Federal.

Todos os seres humanos, precisam de uma proteção e de segurança para que as mesmas possam se desenvolver e alcançar o bem estar físico mental e social. O direito é algo a ser construído socialmente, por meio da participação do estado, da sociedade, da escola e da família. As questões da insegurança pública é um grave problema que afeta a todos. E atualmente as escolas não tem sido mais um ambiente seguro como em outrora.

A efetivação dos direitos é de responsabilidade da legislação brasileira, onde a mesma afirma que a educação, saúde, moradia e segurança são direitos de todos. No entanto, poucos tem desfrutando desse direito com dignidade e respeito. Efetivar os direitos das crianças e dos adolescente é algo desafiador, e que não está nas mãos de um líder ou de representante político, mais na mãos de todos.

A sociedade civil, tem um enorme e desafiador papel quando se trata da área da educação e da proteção social. Os deveres dos diversos atores sociais na efetivação dos direitos dos mais jovens é crucial, pois quando todos colaboram em prol de um objetivo comum, todo o trabalho se torna facilitador. O papel do Estado, das empresas, das famílias e da sociedade civil é primordial para assegurar os direitos das criança e dos adolescente.

O desenvolvimento da educação e da proteção social em nosso país, apresenta também dados estatísticos preocupantes, que ilustram os principais avanços e desafios, mas também alguns retrocessos. Na área da infância e da juventude há muito há ser feito, há muito a ser intervindo para se consolidar uma educação equitativa, além dos demais direitos que são básicos a todos. Para Ladeira (2009) o reconhecimento de direitos sociais no corpo da Constituição Federal é a responsabilidade do Estado brasileiro, porém há uma grande distância entre o que está previsto no papel, e o que está sendo vivenciado na prática.

\section{CONSIDERAÇÕES FINAIS}


Assim é de suma importância, obter o conhecimento sobre noções sobre os direitos das crianças e adolescentes. Dessa forma, é relevantes a tomada de decisões e a resolução de problemas para que, tais direitos cheguem de fato nesse público em especifico de forma equitativa. Dessa forma, há muito a ser discutido e aprendido, bem como muitos tabus e mitos, que precisam ser quebrados, pois muitas das vezes não se sabe ao certo nem, quais são os direitos e quais são os deveres.

Assim, é de fundamental importância, que todos os agentes educacionais construam seu papel em prol da efetivação dos direitos humanos e escolares. Além disso, a escola, a família, a sociedade e o estado precisam estarem aptos e preparados para intervir com sabedoria e com eficácia, para que os altos índices de crimes de violação de direitos sejam amenizados.

O cenário da sociedade, é preocupante, uma vez que, são apresentados inúmeros relatórios e registro de muitas violências, negligencias e violação de direitos contra crianças e adolescentes. Foi abordado também que a questão social e a efetivação dos direito é uma batalha travada constante que cada um precisa lutar em prol da efetivação dos mesmo.

Percebeu se ainda, que muitos são os desafios encontrados para se alcançar esses direitos, porem eles precisam ser alcançados e usufruídos por todos. O trabalho mostrou também, que a educação e a reeducação é um processo sempre transformador e desafiador, e ao falar de direitos eles precisam ser entendidos e garantidos a todos.

Assim, governos, sociedade, escolas e famílias juntos podem alcançar um maior rendimento e desenvolvimento, quando são traçadas metas e objetivos precisos, no que se refere a aquisição dos direitos . Dessa forma, os resultados serão concretizados quando houver a soma de todos em prol de um objetivo comum.

Por fim, em resposta ao objetivo inicial e a situação problema aqui proposta, conclui-se que o objetivo foi atingido, pois a partir dessa discussão foi possível refletir de forma ampla e benéfica sobre a temática, percebendo a relevância dos direitos que nossas crianças e adolescente conquistaram ao longo da história. Como sugestão, indica-se que novos estudos sejam realizados dentro dessa importante temática, para que sejam aprofundados outros aspectos que estão contextualizados com a temática.

\section{REFERENCIAS}


ANDERSON, P. Balanço do neoliberalismo. In: SADER, E.; GENTILLE, P. (Orgs.). Pós-neoliberalismo: as políticas sociais e o Estado democrático. 8. ed. São Paulo: Paz e Terra, 2008.

ALVES, Rubem. Os quatro pilares: aprender a aprender. v.1. São Paulo: Atta mídia e educação, 2008. DVD.

ATLAS DA VIOLÊNCIA. Os estupros com crianças e adolescentes entre 13 e 15 anos já forma forçados a ter relação sexual. O percentual para meninos foi de $3,7 \%$ e para as meninas de 4,3\%. Disponível em: http://www.ipea.gov.br/atlasviolencia.

ABRAMOWICZ, A.; RODRIGUES, T.C.; CRUZ, A.C.J. A diferença e a diversidade na educação. Contemporânea, São Carlos, n. 2, p. 85-97, ago.-dez. 2011.

BAJAJ, M. Schooling for Social Change: The Rise and Impact of Human Rights Education in India. New York: Continuum, 2011.

BRANDÃO, Carlos Rodrigues. O que é educação. São Paulo. Editora Brasiliense, 2013. Disponível em: https://books.google.com.br/books?hl=pt-

$\mathrm{BR} \& \mathrm{lr}=\& \mathrm{id}=\mathrm{wmgvDwAAQBAJ} \& \mathrm{oi}=\mathrm{fnd} \& \mathrm{pg}=\mathrm{PT} 3 \& \mathrm{dq}=\mathrm{BRAND} \% \mathrm{C} 3 \% 83 \mathrm{O},+\mathrm{Carlos}+\mathrm{R}$ odrigues.+O+que+\%C3\%A9+educa\%C3\%A7\%C3\%A30.+S\&ots=lzaQNkRM3z\&sig=g p2YH11idjfjpdgj2z63c19N1k\#v=onepage\&q=BRAND\%C3\%83O\%2C\%2oCarlos\%2OR odrigues.\%20O\%20que\%20\%C3\%A9\%20educa\%C3\%A7\%C3\%A30.\%20S\&f=false. Acesso em 06 de Maio de 2018.

BRASIL. Constituição da Republica Federativa do Brasil. Brasília: Senado Federal, 1988.

BRASIL. Lei no 10.172, de o9 janeiro de 2001. Aprova o Plano Nacional de Educação e dá outras providências. Diário Oficial da República Federativa do Brasil. Brasília, DF, 2001.

BRASIL. Decreto-Lei no 6.094 de 24 de abril de 2007. Dispõe sobre a implementação do Plano de Metas Compromisso Todos pela Educação, pela União Federal, em regime de colaboração com Municípios, Distrito Federal e Estados, e a participação das famílias e da comunidade, mediante programas e ações de assistência técnica e financeira, visando a mobilização social pela melhoria da qualidade da educação básica. Diário Oficial da República Federativa do Brasil. Brasília, DF, 2007.

BRASIL. O plano de desenvolvimento da educação: análise do projeto do MEC. Educação e Sociedade, vol. 28, n. 100 - Especial, p. 1231-1255, Campinas, 2007.

CARNOY, Martins. Mundialização e Reforma na Educação. Brasília, UNESCO, 2002.

CORTELAZZO, I. B. de C. Ensinar e Aprender: as duas faces da educação. In: Colaboração, Trabalho em Equipe e as Tecnologias de Comunicação: Relações de proximidade em cursos de pós-graduação: Tese de Doutorado - Faculdade de Educação da Universidade de São Paulo, 2000.

CHUNG, Nathalie Maia. A alienação parental sob a perspectiva do direito fundamental à convivência familiar saudável. Revista Âmbito Jurídico. No 148 - Ano 
XIX - maio/2016.Da guarda compartilhada. In: Âmbito Jurídico, Rio Grande, XV, n. 99, abr 2012. Disponível em:

http://www.ambitojuridico.com.br/site/?n_link=revista_artigos_leitura\&artigo_id= 11311. Acesso em out 2015.

DECLARAÇÃO Universal dos Direitos Humanos. Nações Unidas, 1948. Disponível em: <http://www.direitoshumanos.usp.br/index.php/Declara\%C3\%A7\%C3\%A3oUniversal-dos-Direitos-Humanos/declaracao-universal-dos-direitoshumanos.html>. Acesso em: 03 mar. 2019.

FEITOSA, André, Luís de Oliveira. O homem e sua liberdade-Definição paradoxal do humano na filosofia de Jean-Paul Sartre. Rio de Janeiro. Dissertação de mestrado. Departamento de Filosofia, PUC-Rio77,p.2005.

GARCIA, E. G. VEIGA, E.C. Psicopedagogia e a teoria modular da mente. São José dos Campos: Pulso. 2006.

GHIRALDELLI, Paulo Júnior. As concepções de infância e as teorias educacionais modernas e contemporâneas. Disponível em: www.filosofia.pro.br/textos/infancia.htm. Acesso em: 3 maio, 2019.

IBGE - INSTITUTO BRASILEIRO DE GEOGRAFIA E ESTATÍSTICA. Pesquisa sobre a adoção de crianças e adolescente no pais 2017. Rio de janeiro, 2002.

. Indicadores Sociais: uma análise do burocracia e da lentidão nos processos de adoção. Resultados do universo do Censo Demográfico 2017. Rio de Janeiro: IBGE, 2011. (Estudos e Pesquisas: informação demográfica e socioeconômica, n. 28).

IPEA - INSTITUTO DE PESQUISA ECONÔMICA APLICADA. Brasil em desenvolvimento no combate ao analfabetismo: Estado, planejamento e políticas públicas. Brasília: Ipea, 2010.

INEP, Instituto Nacional de Estudos e Pesquisas Educacionais Anísio Teixeira, $<$ http://portal.inep.gov.br/visualizar/-/asset_publisher/6AhJ/content/pesquisaaponta-queda-do-analfabetismo?redirect=http\%3a\%2f\%2fportal.inep.gov.br\%2f $>$. Acesso em: 13 de out. 2014.

Instituto Nacional de Estudos e Pesquisas Educacionais Anísio Teixeira (INEP),2017. LUZURIAGA, Lorenzo. História da educação e da pedagogia. 15ed. São Paulo:Ed. Nacional, 1984.

LDB - Lei nº 9.394, de 20 de dezembro de 1996, 11 a ed. Ministério da Educação, 1996.

MANACORDA, Mario Alighiero. Marx e a pedagogia moderna. Campinas, SP: Editora Alínea, 2007. 
MCCOWAN, T. Reframing the universal right to education. Comparative Education, v. 46, n. 4, p. 509-525, 2010. MCCOWAN, T. Education as a human right: principles for a universal entitlement to learning. London: Bloomsbury, 2013. OSLER, A.; STARKEY, H. Teachers and Human Rights Education. Stoke-on-Trent: Trentham, 2010.

NUNES, R.A.C. História da educação na antiguidade cristã: o pensamentoeducacional dos mestres e escritores cristãos no fim do mundo antigo. São Paulo:1978.

OLIVEIRA, Adão Francisco de. Políticas públicas educacionais: conceito e contextualização numa perspectiva didática. In: OLIVEIRA, Adão Francisco de. Fronteiras da educação: tecnologias e políticas. Goiânia-Goiás: PUC Goiás, 2010.

ORGANIZAÇÃO NÃO GOVERNAMENTAL Save the Children dos Estados Americanos, Convenção Interamericana para a Prevenção, Punição e Erradicação da Violência contra a crianças Mulher ("Convenção de Belém do Pará"), 2016

PEREIRA, P. A. P. Mudanças estruturais, política social e papel da família: crítica ao pluralismo de bem-estar. In: SALES, M. A.; MATOS, M. C.; LEAL, M. C. (Orgs.). Política social, família e juventude: uma questão de direitos. 2. ed. São Paulo: Cortez, 2006, p. 25-42.

RODRIGUES, G. A e NUNES, R. A. F, Estado democrático de direito: conceito, história e contemporaneidade. Disponível em Acesso em 01 de Março de 2019.

RIEDEL, M. Between Tradition and Revolution. Cambridge: Cambridge University Press, 1984.

SANTOS, Marcos .Pereira

dos. $<$ http://www.planetaeducacao.com.br/portal/artigo.asp?artigo=2340 $>$. Acesso em: 3 set. 2014 .

SAVIANI, Dermeval. A nova lei da educação: trajetória, limites e perspectivas. 5 ed. Campinas (SP): Autores Associados, 1999. (Coleção educação contemporânea)

SAVIANI, Dermeval. Da nova LDB ao novo plano nacional de educação. 4ed. Campinas: Autores Associados, 2002.

SARLET, Ingo Wolfang. Dignidade da pessoa humana e direitos fundamentais na Constituição Federal de 1988. Porto Alegre: Livraria do Advogado Ltda, 2002.

SEN, A. Elements of a Theory of Human Rights. Philosophy and Public Affairs, v. 32, n. 4, p. 315-356, 2004.

SOUSA, Eliane Ferreira de. Série IDP - Direito à Educação: requisito para o desenvolvimento do país. 1. ed. São Paulo: Saraiva, 2010.

VIEIRA, Rejane Esther. As Fases Históricas Do Estado De Direito No Mundo E No Brasil E Sua Relação Com A Administração Pública. Disponível em Acesso em 03 de Março de 2010. 
TODOS PELA EDUCAÇÃO. Missão, objetivos e princípios. s/d. Disponível em: $<$ http://www.todospelaeducacao.org.br>. Acesso em dezembro de 2019.

2018 - Educar na era planetária: o pensamento complexo como método deaprendizagem no erro e na incerteza humana (Acesso restrito ao PDF - por motivos dedireitos autorais)

<http://unesdoc.unesco.org/images/o013/o01316/131642por.pdf>2018 - Escola 2018<http://www.escola2018.org.br >2018 -

UNICEF. Chamada "A FAMILIAR FACE: Violence in the lives of children and adolescents", disponível no link:

https://www.unicef.org/publications/files/Violence_in_the_lives_of_children_and _adolescents.pdf.

WALDRON, F.; RUANE, B. Human Rights Education: Reflection on Theory and Practice. Dublin: The Liffey Press, 2011.

\section{Sobre o autor}

Bruno Freitas Santos - Graduado em Letras (português e inglês) pela Faculdade de Tecnologia e Ciências-BA, 2009, Pós-graduado em Literatura e Linguagem pela Faculdade Evangélica Cristo Rei-PI, 2013. E-mail: bs1926019@gmail.com 